\title{
The Willingness of Residents in Obstetrics and Gynecology to Provide Legal Abortion Services According to their Opinion on how Liberalization of the Abortion Law would affect Abortion Rates
}

\author{
Faúndes $\mathrm{A}^{1 *}$, Pacagnella $\mathrm{RC}^{2}$, Bento $\mathrm{SF}^{3}$, Fernandes $\mathrm{KG}^{2,4}$, Osis $\mathrm{MJD}^{2,4}$, Duarte $\mathrm{GA}^{1}$, Pádua $\mathrm{KS}^{3}$ and Brazilian \\ Abortion Study Group \\ ${ }^{1}$ Campinas Center for Research in Human Reproduction, Campinas, Brazil \\ ${ }^{2}$ Department of Obstetrics and Gynecology, State University of Campinas, Brazil \\ ${ }^{3}$ Professor José Aristodemo Pinotti - Center for Integral Attention to Women (Caism) - State University of Campinas, Brazil \\ ${ }^{4}$ School of Medicine, Jundiaí, Brazil
}

Submission: May 21, 2018; Published: June 21, 2018

"Corresponding author: Anibal Faúndes, Senior Researcher, Campinas Center for Research in Human Reproduction, P.0. Box 6181, 13083-970 Campinas, São Paulo, Brazil, Tel: 55-19-3289-2856; Email: afaundes@uol.com.br

\begin{abstract}
Objective: Bearing in mind the restrictive abortion laws in Brazil, the objective of the present study was to evaluate a possible association between the opinion of Brazilian obstetrics and gynecology residents regarding how liberalization of abortion laws would affect abortion rates and their willingness to provide legal abortion services.

Study design: This was a multicenter survey conducted with residents in obstetrics and gynecology from maternity hospitals in four different regions of Brazil who answered a questionnaire enquiring about their willingness to provide abortion care and their opinion on the effect of the legalization of abortion on the abortion rate, among other socio demographic factors.

Results: Residents who believed that liberalization of the abortion law would result in an increase in the abortion rate were significantly less willing to provide legal abortion services. This association persisted following adjustment for all the other factors associated with residents' willingness to provide abortion services.
\end{abstract}

Conclusion: The belief that legalization of abortion would increase the abortion rate was associated with significantly less willingness to provide abortion services.

Keywords: Legal abortion; Willingness to provide care; Legalization of abortion; Abortion rate; Medical residents; Brazil

\section{Introduction}

The legal conditions under which abortion is permitted differ from country to country [1]. Current legislation in Brazil permits abortion in cases of rape, when the mother's life is in danger and in cases of anencephaly [2]. As in other countries with restrictive abortion laws, many women meeting the conditions required to obtain a safe legal abortion are unable to access services [3].

One of the main obstacles to obtaining access to legal abortion is the unwillingness of physicians, particularly obstetricians and gynecologists, to provide such services [46]. If we want to facilitate access to safe legal abortion care, we should find ways of improving physicians' attitudes by ensuring that they understand that it is our ethical duty to provide legal abortion to every woman requesting termination who complies with the conditions imposed by the law.
One factor possibly associated with reluctance to provide care is the concept that facilitating access to legal abortion contributes towards increasing the abortion rate. As most people would prefer to see a decrease rather than an increase in the number of abortions, that concept may lead to unwillingness to provide care.

There is significant evidence in the literature that facilitating access to safe legal abortion does not increase and, indeed, may reduce abortion rates $[7,8]$. To the best of our knowledge, there are no publications evaluating the proportion of physicians who are aware that abortion rates do not increase following legalization. Consequently, no publications have evaluated a possible association between an individual's opinion regarding how facilitating access to abortion by broadening legislation 
would affect abortion rates and his/her willingness to provide legal abortion services.

The aforementioned considerations led us to conduct a nationwide survey to question Brazilian residents in obstetrics and gynecology regarding their willingness to provide safe abortion care and the factors associated with it, including their opinion on the effect of the liberalization of abortion legislation on abortion rates.

\section{Material and Methods}

This is a multicenter survey of residents from 21 maternity hospitals with residency programs in obstetrics and gynecology, located in four different geographical regions of Brazil. In Brazil, the official residency program in obstetrics and gynecology is of three years' duration, with an additional, optional two years for some sub-specialties such as fetal medicine, oncology, urogynecology and human reproduction. The hospitals selected are part of the Brazilian Network for Studies in Reproductive and Perinatal Health. All these hospitals are obliged to provide safe abortion services to women who meet the conditions determined under current legislation, and the residents are expected to participate in providing these services unless claiming conscientious objection. Residents are able to participate in the care of women requesting legal abortion, including their admission, physical examination, requesting laboratory tests, etc., while not necessarily taking part in performing the abortion. The involvement of the residents in providing safe abortion services was not necessarily the same in the different hospitals participating in this study.

We appointed a local supervisor at each of the participating hospitals, with each supervisor receiving identical training to standardize the data collection procedures. During training, the supervisors received information regarding the study objectives, methodology and ethical aspects, with ample time being given for questions and discussions.

Each resident received a written, 31-item questionnaire to complete. Before the residents agreed to participate in the study, we provided them with information on the study and gave them the opportunity to ask questions. They were free to answer all, some or none of the questions. Anonymity was guaranteed by requesting the participant to deposit his/her questionnaire, completed or otherwise, into a sealed box. The seals on the boxes were broken only at the coordinating center, and the investigators were blinded with respect to the institution from which the box originated. The purpose of this procedure was to ensure participants' privacy by reassuring them that the supervisor would not know whether they had decided to participate or not in the study.
In some hospitals, all the residents were available to answer the questionnaire at the same time; however, in others, residents who were occupied with their duties at that time were able to answer the questionnaire individually later, at a convenient time. The data collection process continued until all the residents had had the opportunity to participate in the study.

The questionnaire included items regarding participants' socio demographic characteristics, their knowledge regarding medical abortion, their personal and professional experiences related to abortion, their attitudes to abortion, their opinion on the effect of legalization on the abortion rate and their willingness to provide an abortion in practice. In the data analysis, the association between the residents' personal characteristics and their willingness to provide safe abortion services was evaluated using the chi-square test.

Next, the association between the residents' opinions on how abortion rates would change following a hypothetical liberalization of the abortion law and their willingness to provide safe abortion services was evaluated. To do so, the residents were divided into two groups according to their opinion on the effect of liberalization of the abortion law: those who believed that the abortion rate would remain constant or would fall, and those who believed that the rate would increase or who declined to express an opinion. We performed a logistic regression analysis that included the factors found to be significantly associated $(p<0.05)$ with willingness to provide safe abortion care in the bivariate analysis, i.e. sex, marital status, having a religion, the importance of religion and the individual's experience of being involved in providing a safe legal abortion. We performed the entire analysis using the R software package [9].

The internal review board of the School of Medical Sciences, State University of Campinas (UNICAMP) approved the study protocol (CAAE: 21177013.3.0000.5404), as did the internal review boards of each of the participating hospitals. The need for signed informed consent was waived considering the nature of the study and to ensure complete confidentiality.

\section{Results}

\section{Characteristics of the sample}

At the time of the interview, there were 530 residents in obstetrics and gynecology in the 21 institutions included in the study. Of these, we invited $83 \%$ to participate in the survey and $77 \%$ returned the questionnaires (404 completed questionnaires and 3 blanks). Table 1 shows the socio demographic characteristics of the respondents.

Over $80 \%$ of the residents had provided care to women admitted to their institute for a legal abortion and over $70 \%$ had actually been involved in performing an abortion (Table 1). 
Table 1: Distribution of the sample of Brazilian residents in obstetrics and gynecology, according to their sociod emographic characteristics and participation in abortion care $(n=404)$.

\begin{tabular}{|c|c|c|}
\hline Characteristics & $\mathbf{n}$ & $\%$ \\
\hline \multicolumn{3}{|l|}{ Sex } \\
\hline Male & 76 & 18.8 \\
\hline Female & 327 & 81 \\
\hline Data missing & 1 & 0.2 \\
\hline \multicolumn{3}{|l|}{ Age (years) } \\
\hline$\leq 27$ & 227 & 56.2 \\
\hline$>27$ & 177 & 43.8 \\
\hline \multicolumn{3}{|l|}{ Marital status } \\
\hline Married & 80 & 19.8 \\
\hline Other & 324 & 80.2 \\
\hline \multicolumn{3}{|l|}{ Religion } \\
\hline Catholic & 230 & 56.9 \\
\hline Spiritualist & 49 & 12.1 \\
\hline Protestant & 33 & 8.2 \\
\hline Other & 6 & 1.5 \\
\hline No religion & 76 & 18.8 \\
\hline Data missing & 10 & 2.5 \\
\hline \multicolumn{3}{|c|}{ Importance of religion in participants' lives } \\
\hline Very important & 119 & 29.4 \\
\hline Of some importance & 254 & 62.9 \\
\hline Of little or no importance & 31 & 7.7 \\
\hline \multicolumn{3}{|l|}{ Year of residency } \\
\hline $1^{\text {st }}$ or $2^{\text {nd }}$ & 274 & 67.8 \\
\hline $3^{\text {rd }}$ to $5^{\text {th }}$ & 130 & 32.2 \\
\hline \multicolumn{3}{|c|}{ Involved in the care of pregnancy termination } \\
\hline No & 72 & 17.8 \\
\hline Yes & 329 & 81.4 \\
\hline Data missing & 3 & 0.8 \\
\hline \multicolumn{3}{|c|}{ Involved in providing pregnancy termination } \\
\hline No & 115 & 28.4 \\
\hline Yes & 286 & 70.8 \\
\hline Data missing & 3 & 0.8 \\
\hline
\end{tabular}

Opinion on the effect of liberalization of the abortion law on abortion rates

Sixty percent of the residents believed that liberalization of the abortion law would lead to an increase in the abortion rate, while $32.6 \%$ believed that the abortion rate would remain constant or decrease. Another $7.4 \%$ failed to express any opinion (data not shown in tables).

Willingness to provide abortion services within current legislation or if legislation were expanded to include protection of the woman's physical health

Around two-thirds of the residents (62.8\%, 245/395) declared that they would be willing to perform a safe abortion within the boundaries of current legislation. Almost half $(48.0 \%$, $189 / 394$ ) would also be willing to provide safe abortion services under more liberal legislation that would permit abortion if the woman's physical health were endangered in addition to those conditions already covered by current legislation (data not included as tables).

\section{Willingness to provide legal abortion services according to residents' socio demographic characteristics}

There was no correlation between gender and willingness to provide abortion care under current legislation; however; male residents were more willing to provide legal abortion 
services if the law were to include the protection of the woman's physical health. Willingness to provide abortion services was also significantly greater among unmarried residents, among those who gave little or no importance to religion, and those who had already performed a legal abortion. Willingness to provide abortion services was greater among those who did not practice any form of religion or who were Catholics compared to those who practiced any other religion.
The difference between the percentages of non-religious residents and Catholic residents who were willing to provide abortion services was of only five percentage points $(72 \%$ versus $67 \%$ ) insofar as current abortion legislation was concerned; however, this difference increased to 14 percentage points $(64 \%$ versus $48 \%$ ) if legislation were to permit abortion to preserve a woman's physical health (Table 2).

Table 2: Association between the characteristics of Brazilian residents in obstetrics and gynecology and their willingness to provide abortion services within current legislation or if legislation were changed to include protection of the woman's physical health.

\begin{tabular}{|c|c|c|c|c|c|c|}
\hline \multicolumn{7}{|c|}{ Willing to Provide Abortion Services } \\
\hline \multirow{2}{*}{ Residents' Characteristics (n) } & \multicolumn{3}{|c|}{ Under Current Legislation } & \multicolumn{3}{|c|}{$\begin{array}{l}\text { If Legislation Included Protection of Woman's } \\
\text { Physical Health }\end{array}$} \\
\hline & n & $(\%)$ & p-value* & n/total & $(\%)$ & p-value* \\
\hline \multicolumn{7}{|l|}{ Sex } \\
\hline Female (319) & 195 & 61.1 & 0.19 & $144 / 318$ & 45.3 & 0.05 \\
\hline Male (75) & 52 & 69.3 & & $44 / 75$ & 58.7 & \\
\hline \multicolumn{7}{|l|}{ Age } \\
\hline$\leq 27$ years $(222)$ & 143 & 64.4 & 0.45 & $110 / 222$ & 49.6 & 0.48 \\
\hline$\geq 28$ years $(173)$ & 105 & 60.7 & & $79 / 172$ & 45.9 & \\
\hline \multicolumn{7}{|l|}{ Marital Status } \\
\hline Married (79) & 37 & 46.8 & 0.001 & $27 / 78$ & 34.6 & 0.01 \\
\hline Other (318) & 211 & 66.8 & & $162 / 316$ & 51.3 & \\
\hline \multicolumn{7}{|l|}{ Religion practiced } \\
\hline Catholic (231) & 155 & 67.1 & 0.001 & $111 / 230$ & 48.3 & 0.002 \\
\hline Spiritualist (49) & 22 & 44.9 & & $17 / 49$ & 34.7 & \\
\hline Protestant (26) & 10 & 38.5 & & $6 / 26$ & 23.1 & \\
\hline Other (13) & 6 & 46.2 & & $6 / 13$ & 46.2 & \\
\hline No religion (76) & 55 & 72.4 & & $49 / 76$ & 64.5 & \\
\hline \multicolumn{7}{|l|}{ Importance of religion in their behavior } \\
\hline Very important (117) & 51 & 43.6 & 0.0001 & $34 / 116$ & 29.3 & 0.0001 \\
\hline Of some importance (247) & 172 & 69.6 & & $134 / 247$ & 54.3 & \\
\hline Of little or no importance (31) & 25 & 80.7 & & $21 / 31$ & 67.7 & \\
\hline \multicolumn{7}{|l|}{ Year of residency } \\
\hline First or second (268) & 162 & 60.5 & & $125 / 267$ & 46.8 & 0.5 \\
\hline Third to fifth (127) & 86 & 67.7 & & $64 / 127$ & 50.4 & \\
\hline \multicolumn{7}{|c|}{$\begin{array}{l}\text { Involved in the care of women requesting legal } \\
\text { abortion during residency }\end{array}$} \\
\hline Not involved (70) & 41 & 58.6 & 0.41 & $31 / 70$ & 44.3 & 0.5 \\
\hline Involved (323) & 206 & 63.8 & & $157 / 322$ & 48.8 & \\
\hline \multicolumn{7}{|c|}{ Involved in providing legal abortion services } \\
\hline Not involved (113) & 61 & 54 & 0.02 & $43 / 112$ & 38.4 & 0.02 \\
\hline Involved (280) & 186 & 66.4 & & $146 / 280$ & 52.1 & \\
\hline
\end{tabular}

${ }^{*}$ Chi-square test 
Willingness to provide legal abortion services according to the individual's opinion on how abortion rates would change if the abortion law became more liberal

The proportion of residents willing to provide legal abortion services was lowest among those who failed to express an opinion or who believed that facilitating abortion by making it

Table 3: Association between the opinion of Brazilian residents in obstetrics and gynecology on changes in the abortion rate if abortion law became more liberal and his/her willingness to provide safe abortion services within the confines of current legislation and also if legislation were changed to include preservation of the woman's physical health.

\begin{tabular}{|c|c|c|c|c|c|c|}
\hline \multicolumn{7}{|c|}{ Willing to Provide Abortion Services } \\
\hline & \multicolumn{3}{|c|}{ Under Current Law } & \multicolumn{3}{|c|}{$\begin{array}{l}\text { If Legislation Included Preservation of } \\
\text { the Woman's Physical Health }\end{array}$} \\
\hline & n/total & $(\%)$ & p-value* & n/total & $(\%)$ & p-value* \\
\hline Declined to express an opinion & $12 / 29$ & 41.4 & 0.001 & $9 / 29$ & 31.0 & 0.001 \\
\hline Abortion rate would increase & $134 / 236$ & 56.8 & & $97 / 236$ & 41.1 & \\
\hline Abortion rate would remain the same & $77 / 105$ & 73.3 & & $62 / 105$ & 59.1 & \\
\hline Abortion rate would decrease & $19 / 23$ & 82.6 & & $17 / 23$ & 73.9 & \\
\hline
\end{tabular}

* Chi-square test

The association between believing that the implementation of more liberal abortion laws would result in abortion rates remaining the same or decreasing and a greater willingness to provide abortion services remained significant following adjustment for all the other factors associated with willingness to provide services, both under current legislation $(\mathrm{OR}=2.17$; 95\%CI: 1.31-3.62; $\mathrm{p}<0.005$ ) and if the law were amplified to include preservation of the pregnant woman's physical health $(\mathrm{OR}=2.16$; 95\%CI: 1.17-4.01; $\mathrm{p}<0.02)$.

\section{Discussion}

The results of this study show that around 40\% of Brazilian residents in obstetrics and gynecology are unwilling to provide safe abortion services, even in cases covered by current legislation. Findings also show that most residents were unaware of how abortion rates have changed in the countries in which the abortion laws have been liberalized. This lack of accurate information was found to be strongly associated with their unwillingness to provide safe, legal abortion services.

The proportion of residents in this study who expressed their willingness to provide safe abortion services was much higher than figures reported in other settings, both among residents and medical students $[10,11]$. On the other hand, the proportion of residents willing to provide abortion services within the current legal framework was lower than among physicians in general in Mexico, where $71.1 \%$ were willing to provide abortion services for women who had been raped [4].

The present finding that residents in obstetrics and gynecology who had been involved in providing legal abortion services during their training were more willing to provide such services in the future is in agreement with several other studies legal would increase the abortion rate. Willingness to provide a legal abortion was higher among those who believed that the abortion rate would remain constant and highest among the residents who believed that the abortion rate would decrease following legalization (Table 3). The percentage of residents willing to provide safe legal abortion care was twice as high in this last group compared to those who failed to express an opinion.
$[4,12]$. It is impossible, however, to know whether they had already been involved in providing abortion services because they were more willing to provide such services or the other way around.

To the best of our knowledge, no papers have been published on the opinion of residents in obstetrics and gynecology, of physicians or of any other healthcare professionals with respect to the expected effect of the liberalization of abortion legislation on abortion rates. Therefore, the present study contributes significantly to current knowledge by showing that less than a third of Brazilian residents in obstetrics and gynecology believe that liberalization of the abortion law would result in no change or even in a reduction in the abortion rate. Although this finding cannot be generalized to settings in other countries, it is possible that the situation may not be very different in many other developing countries with restricted abortion laws and high abortion rates [13].

A limitation of the present study is that although it is based on a convenience sample of residents from the most prestigious residency program in Brazil, it is not a randomly selected representative sample of all Brazilian residents in obstetrics and gynecology. On the other hand, this study collected data from the largest sample of residents in obstetrics and gynecology so far evaluated in Latin America.

Finally, the present results confirm the hypothesis that the erroneous concept that improving access to safe abortion would increase the abortion rate is a factor strongly associated with unwillingness to provide safe abortion services. These findings support the idea that greater effort spent in disseminating evidence that the liberalization of abortion laws does not lead to an increase in abortion rates and may indeed be instrumental 
in reducing these rates could contribute towards decreasing physicians' resistance to providing safe, legal abortion services.

\section{Conclusion}

Most residents in obstetrics and gynecology still believe that facilitating safe abortion would lead to an increase in the abortion rate, with that belief being strongly associated with unwillingness to provide safe abortion services. There is an obligation to publish and disseminate the existing evidence that legalization of abortion and facilitating access to safe abortion do not result in an increase in the abortion rate. The findings of the present study suggest that being aware of these facts may decrease physicians' resistance to providing services and reduce women's difficulties in gaining access to safe abortion within the limits of the law.

\section{Acknowledgement}

The authors are grateful for the collaboration/opinion of all the residents in obstetrics and gynecology and the maternity hospitals located in the four different geographical regions of Brazil that provide the services described in this article.

Collaborators (21) The Brazilian Abortion Study Group: Carlos Augusto Santos de Menezes, Claudio Sérgio Medeiros Paiva, Dênis José do Nascimento, Edilberto Alves Pereira Rocha da Silva, Elaine Christine Dantas Moisés, Fátima Aparecida Henrique Lotufo, Fernando Artur Carvalho Bastos, Francisco Edson de Lucena Feitosa, Francisco José Machado Viana, Francisco Lázaro Pereira de Sousa, Ione Rodrigues Brum, Joaquim Luiz de Castro Moreira, Marcelo Marques de Souza Lima, Mario Dias Corrêa Júnior, Marla Niag dos Santos Rocha, Nelson Sass, Olímpio Barbosa de Moraes Filho, Rosiane Mattar, Silvana Maria Quintana, Vera Therezinha Medeiros Borges, Yalli Coelho.

\section{References}

1. Myers JE, Seif MW (2010) Global perspective of legal abortion-trends analysis and accessibility. Best Pract Res Clin Obstet Gynaecol 24(4): 457-466.
2. Diniz D (2007) Selective abortion in Brazil: the anencephaly case. Dev World Bioeth 7(2): 64-67.

3. Amado ED, Calderón García MC, Cristancho KR, Salas EP, Hauzeur EB (2010) Obstacles and challenges following the partial decriminalization of abortion in Colombia. Reprod Health Matters 18(36): 118-126.

4. Silva M, Billings DL, García SG, Lara D (2009) Physicians' agreement with and willingness to provide abortion services in the case of pregnancy from rape in Mexico. Contraception 79(1): 56-64.

5. Harris LH, Cooper A, Rasinski KA, Curlin FA, Lyerly AD (2011) Obstetrician-gynecologists' objections to and willingness to help patients obtain an abortion. Obstet Gynecol 118(4): 905-912.

6. Coppola F, Briozzo L, Nozar F, Fiol V, Greif D (2016) Conscientious objection as a barrier for implementing voluntary termination of pregnancy in Uruguay: gynecologists' attitudes and behavior. Int Gynaecol Obstet 134(S1): S16-S19.

7. Benagiano G, Pera A (2000) Decreasing the need for abortion: challenges and constraints. Int J Gynaecol Obstet 70(1): 35-48.

8. Faúndes A, Shah HI (2015) Evidence supporting broader access to safe legal abortion. Int J Gynaecol Obstet 131(Suppl 1): S56-S59.

9. R Core Team (2017) R: A language and environment for statistical computing. R Foundation for Statistical Computing, Vienna, Austria. [accessed 06 march 2017]. Available from: http://www. www.Rproject.org/

10. Wheeler SB, Zullig LL, Reeve BB, Buga GA, Morroni C (2012) Attitudes and intentions regarding abortion provision among medical school students in South Africa. Int Perspect Sex Reprod Health 38(3):154163.

11. Myran DT, Carew CL, Tang J, Whyte H, Fisher WA (2015) Medical students' intentions to seek abortion training and to provide abortion services in future practice. J Obstet Gynaecol Can 37(3): 236-244.

12. Steinauer J, Landy U, Filippone H, Laube D, Darney PD (2008) Predictors of abortion provision among practicing obstetrician-gynecologists: a national survey. Am J Obstet Gynecol 198(1): 39.e1-6.

13. Sedgh G, Singh S, Henshaw SK, Bankole A (2011) Legal abortion worldwide in 2008: levels and recent trends. Int Perspect Sex Reprod Health 37(2): 84-94.

\section{Your next submission with Juniper Publishers} will reach you the below assets

- Quality Editorial service

- Swift Peer Review

- Reprints availability

- E-prints Service

- Manuscript Podcast for convenient understanding

- Global attainment for your research

- Manuscript accessibility in different formats

( Pdf, E-pub, Full Text, Audio)

- Unceasing customer service

Track the below URL for one-step submission https://juniperpublishers.com/online-submission.php 